\title{
A ESCOLHA PELA DOCÊNCIA E SUAS RELAÇÕES DE FORÇAS: COMPREENSÕES E MULTIPLICIDADES NO CERNE DE UM GRUPO DE ESTUDOS E PESQUISAS EM EDUCAÇÃO
}

\author{
The Choice for Teaching and its Relationships of Strengths: Understandings and \\ Multiplicities At The Heart of a Group Of Studies and Research in Education
}

Fernanda Monteiro Rigue ${ }^{1}$

Alice Copetti Dalmaso ${ }^{2}$

\begin{abstract}
Resumo: Este estudo visa identificar e compreender que forças contingenciaram a escolha pela docência enquanto profissão pesquisadoras vinculadas a um Grupo de Estudos e Pesquisas em Educação. O fazemos a partir de uma escrita ensaística (LARROSA, 2003) que permite vislumbrar as multiplicidades que as levaram a escolher a profissão docente, tramando algumas linhas que constituem a malha de um ambiente formativo que é tecido em meio às diferentes trilhas da existência das pesquisadoras no contexto universitário brasileiro. Resulta do estudo que: os vínculos e as experiências vivenciadas no cerne dos ambientes familiares toma lugar de destaque em como as integrantes do Grupo perceberam e buscaram sua futura ação profissional; as afetações que as professoras produziram em seus corpos como força importante para a escolha da docência como profissão; a experimentação vivenciada na infância, nas brincadeiras, nas aulas direcionadas às bonecas e aos irmãos, como promotora de uma alegria que ficou registrada na memória corporal dessas professoras e futuras professoras; as representações sociais que pairam sob a docência por vezes se caracterizam como um ponto problemático que, por vezes, impede e dificulta a opção pela formação superior em licenciatura. Logo, conclui-se que a escolha pela profissão docente é marcada por diferentes polifonias e multiplicidades que demandam cultivarmos uma permanente atitude ética que respeite e permita às integrantes do Grupo estarem se modulando livremente, com base em suas leituras de mundo e também de proximidade com as versões multifacetadas da docência.
\end{abstract}

Palavras-chave: Processo formativo. Docência. Malha.

\begin{abstract}
This study aims to identify and understand which forces contingent on the choice of teaching as a profession of researchers linked to a Group of Studies and Research in Education. We make this from an essay writing (LARROSA, 2003) that allows us to glimpse the multiplicities that led them choose the teaching profession, weaving some lines which build the mesh of a formative environment that is woven amidst the different paths of the researchers'

\footnotetext{
${ }^{1}$ Doutora em Educação pela Universidade Federal de Santa Maria (UFSM). Licenciada em Química pelo Instituto Federal Farroupilha (IFFar). Professora no curso de Licenciatura em Química do Instituto de Ciências Exatas e Naturais do Pontal - Universidade Federal de Uberlândia (ICENP/UFU). Orcid: http://orcid.org/0000-0003-24037513. E-mail: fernanda_rigue@hotmail.com

2 Pós-Doutorado pelo Laboratório de Estudos Avançados em Jornalismo do Núcleo de Desenvolvimento da Criatividade, da Universidade Estadual de Campinas (UNICAMP). Doutorado e Mestrado em Educação pela Universidade Federal de Santa Maria (UFSM). Bacharel e Licenciada em Ciências Biológicas pela Universidade Federal de Santa Maria (UFSM). Professora Adjunta no Departamento de Metodologia de Ensino da UFSM. Orcid: http://orcid.org/0000-0002-4447-0958. E-mail: alicedalmaso@gmail.com.
} 
existence within the Brazilian university context. It is results from the study that: the bonds and the experiences lived in the heart of family environments take a prominent place in how the members of the group perceived and sought their future professional action; the affectations that the teachers produced on their bodies as an important force in choosing teaching as profession; the experimentation experienced in childhood, in games, in classes directed at the dolls and siblings, as a promoter of a joy that was registered in the bodily memory of these teachers and future teachers; the social representations that hover over teaching are sometimes characterized as a problematic point that, at times, prevents and hinders the option for higher education in a degree. Therefore, it is concluded that the choice of the teaching profession is marked by different polyphonies and multiplicities that demand that we cultivate a permanent ethical attitude that respects and allows the members of the group to be freely modulating, based on their readings of the world and also of proximity to the multifaceted versions of teaching.

Keywords: Formative process. Teaching. Mesh.

\section{Introdução}

Os percursos formativos que se estabelecem ao longo de uma trajetória de constituição docente são como uma grande malha, a qual, na compreensão teórico-conceitual de cunho antropológico, entrelaça-se nas relações humanas e não humanas na medida em que os seres se movimentam no mundo (INGOLD, 2015).

A noção de malha trazida por Tim Ingold pensa as infinitas interações e relações nas quais estamos invariavelmente imersos e somos copartícipes no mundo: "Organismos e pessoas, então, não são tanto nós em uma rede quanto nós em um tecido de nós, cujos fios constitutivos, conforme se amarram a outros fios, em outros nós, compreendem a malha" (INGOLD, 2015, p. 120). Há uma mútua imbricação, interdependente, no entrelaçamento entre seres vivos e não vivos, onde pessoas, animais, coisas, entram em fluxos e contrafluxos de processos de vida, produzindo um grande emaranhado, um grande tecido, sem início, meio e fim. Têm-se, assim, múltiplos emaranhados que constituem a malha, singularidades únicas, específicas e indispensáveis para que ela se torne possível, vívida e continuamente em formação.

Se pudermos pensar acerca da referida noção e agenciá-la à formação docente, interessa vislumbrar que essas linhas-existências, as quais produzem uma malha, muitas vezes esparsas, que se emaranham e entrecruzam antes mesmo do início de uma formação superior, produzem uma série de atravessamentos, marcas e rastros no transcorrer dos processos educacionais empreendidos ao longo do movimento de formação docente, que acontece no lócus das instituições de ensino superior.

Como sugere Ingold (2015):

[...] as pessoas não são seres que se movem, elas são os seus movimentos. É nos seus próprios padrões de atividade que a sua presença se encontra. E lugares não são tanto localidades para serem conectados quanto formações que surgem no processo de movimento, como redemoinhos em uma corrente de rio. Em suma, nesse mundo nomes não são subjetivos, mas verbos: cada um descreve um acontecimento (INGOLD, 2015, p. 247).

Reconhecendo a intensidade de forças moventes que constituem as múltiplas linhas de um trajeto de constituição profissional docente e que as "[...] coisas são as suas relações" (INGOLD, 2015, p. 119) é que o presente estudo emerge, tendo como principal anseio 
identificar e compreender que forças contingenciaram a escolha pela docência enquanto profissão de pesquisadoras vinculadas ao Grupo de Estudos e Pesquisas em Educação Fiandar, da Universidade Federal de Santa Maria (UFSM-RS). O fazemos com vistas a conhecer o que levou as integrantes do Grupo a escolherem a profissão, tecendo algumas linhas que constituem a própria malha do Grupo, um ambiente formativo que é tecido em meio às diferentes trilhas da existência das pesquisadoras no contexto universitário brasileiro.

Quando nos colocamos em contato com essa busca pela aproximação e reconhecimento dessas linhas de força que atravessam a escolha pela docência das integrantes do Grupo, pensamos sua potência na medida em que as interações e encontros que se dão em um processo formativo operam como "[...] malha de linhas emaranhadas de vida, crescimento e movimento" (INGOLD, 2015, p. 111).

O processo formativo, assim como a malha da vida, está, como aponta Ingold (2015), em permanente crescimento, em nascimento contínuo. Ao mesmo tempo, em permanente metamorfose - variação - infinidade de nascimentos que inauguram transformações do próprio corpo que flui no/com o mundo (COCCIA, 2020). Nesse tom, o processo de formação docente também pode ser percebido como um movimento que se desdobra e se estende ao mundo que nós habitamos ao longo de nossas múltiplas linhas de atividade: ações, pensamentos, emoções, vínculos, palavras e gestos, que vão crescendo e nascendo continuamente, e, por sua vez, instaurando modos de viver.

Consideramos que essa caminhada investigativa assenta um terreno potente no que tange à exploração de um território de estudos e pesquisas na área da Educação, tendo em vista que esse ambiente formativo trata de um espaço de vinculação e confiança nos espaços universitários, o que transversaliza uma possibilidade latente de interlocução significativa em termos de autoeducação ${ }^{3}$.

Compreendemos relações de forças na perspectiva de Michel Foucault (2015), enquanto contingências, combinações de acontecimentos que culminam em tomadas de algumas decisões, conjunto de decisões, em detrimento de outras. Mobilidade intensiva de engendramentos que se exercem sob os corpos, inscrevendo-se neles. Ademais, ressaltamos que o texto está escrito no gênero feminino porque o Grupo, desde sua emergência, é formado apenas por sujeitos que se identificam como mulheres.

Em termos metodológicos, este fazer escritural se situa como uma escrita ensaística (LARROSA, 2003). Para tanto, inicialmente são tecidos aspectos inerentes ao Grupo de Estudos e Pesquisas, suas ênfases e especificidades. Em seguida, será desenvolvida uma atenção às materialidades-escritas produzidas pelas integrantes do Grupo quanto a uma problemática que foi compartilhada e submetida para resposta voluntária das discentes no intervalo de quase um mês, no ano de 2021. A problemática foi a seguinte: "Que relações de forças concorreram para que você buscasse a formação inicial docente?". Com base nessa pergunta, encontramo-nos com as narrativas produzidas pelas integrantes do Grupo (aqui denominadas de Fiandeiras), constituindo, posteriormente, ressonâncias afetivas e problematizadoras das narrativas. As referidas escritas foram colocadas em fluxo dentro de um prisma de atenção para suas relações de forças e atravessamentos, buscando estabelecer um movimento em que as autoras também fossem afetadas por suas potencialidades e especificidades.

Constituindo, então, uma escrita-pensamento ensaística, mergulhamos na malha que compõe o processo de constituição docente de professoras e futuras professoras. Aspecto que

\footnotetext{
3 "Como modos de modificação de alguém sobre si mesmo" (CORRÊA, 2014, p. 02).
} 
consideramos extremamente significativo para situar o terreno rizomático de forças que as trouxeram até um contexto de formação e pesquisa em educação.

\section{Grupo de Estudos e Pesquisas em Educação como espaço formativo}

O Grupo de Estudos e Pesquisas em Educação Fiandar foi criado em 2018, e, em seu registro no site do Conselho Nacional de Desenvolvimento Científico e Tecnológico (CNPq), apresenta como repercussão "Articular estudos em ciências, arte, educação e cultura, atrelados aos estudos culturais e às filosofias da diferença", reunindo integrantes externos e internos à universidade: estudantes dos cursos de Pedagogia e Ciências Biológicas, professoras de Artes Visuais, docentes do ensino superior, mestras e doutoras em educação, com suas pesquisas multidisciplinares.

A história recente do surgimento do Grupo nos incita a revisitar seus desejos de fundação. A sensação era de poder criar um espaço de comunhão de vontades, onde docentes, estudantes, pesquisadores, para além de suas identidades provisórias, pudessem se encontrar e produzir um tecido de relações acadêmicas, conduzindo pesquisas, escritas e afetos que dessem a pensar a educação, mas empenhados em capturar no coletivo aquilo que

[...] vibra, o que passa, o que acontece na multiplicidade. Nesse sentido, tudo pode ser material de ser deglutido, bem como a criação de um espaço-território onde afetos, narrativas, por vezes não acadêmicas e científicas, mas somente como sensação momentânea, como acontecimento, podem chegar, permanecer e cocriar o tecido do mundo. (DALMASO; RIGUE, 2020, p. 67).

Para aprender a costurar esse tecido a tantas mãos, o desejo nos fazia angariar leituras e práticas que dessem conta de"[...] singularizar modos de habitar a formação inicial de professores no contexto universitário, uma chance de olhar para problemáticas que não costumam ter a possibilidade de aparecer nos enunciados e discursos universitários". (DALMASO; RIGUE, 2020, p. 64).

No processo de desenvolvimento do Grupo, tratava-se de aprender a habitar - e não meramente ocupar - um lugar em que se busca cultivar cuidado e atenção com os seres que constituem uma malha de profissionais da educação de diversas áreas e ofícios, e que chegam até o Grupo com diferentes volições e expectativas relacionadas à grande área da Educação. Já que "o ocupante ocupa uma posição em um mundo já pronto; o habitante contribui através da sua atividade para a contínua regeneração do mundo (INGOLD, 2000a:149)" (INGOLD, 2015, p. 247).

Para tanto, notoriamente, encaramos desde sempre a necessidade de não sustentação de qualquer representação - imagem ou enunciado demasiadamente professoral ou hierárquico de nossos lugares de liderança, - a fim de desidealizar e descolonizar as conjunturas sobremaneira enrijecidas do fazer acadêmico-científico canônico nos espaços universitários. Nessa atmosfera,

[...] flechas de inquietações surgiram: que coisas e afetos outros podemos produzir dentro do espaço universitário? Que figuras outras podemos e queremos sustentar? A quem e como queremos movimentar com nossas ações, nossos gestos, nossos discursos? Que facetas levamos com a gente e que oferecemos aos outros, num eco ininterrupto do que fazemos no mundo? Como se enxergar um pouco mais, produzindo intervalos onde possa haver vida, afeto, devir, produção de uma ética do cuidado na universidade? (DALMASO; RIGUE, 2020, p. 65). 
Acreditamos que a potência daquilo que tem sido produzido no referido Grupo tenha relação estreita com a compreensão de que "[...] seu impulso não consiste em alcançar um termo, mas em seguir em frente" (INGOLD, 2015, p. 137), arregimentando desejos e fazendo nascer mundos ainda não pensados em educação. Seguir percebendo as texturas e também correntes - relações de forças - que interpelam cada uma de nós ao longo desse processo formativo de estudos e de pesquisas, justamente por estarmos habitando juntas essa malha formativa, o que denota que essa prática de habitação também é parte daquilo que nós somos e daquilo que desejamos ser. Um nascimento contínuo que é coletivo e articulado, indo ao encontro de desenhar o mundo, como afirma Coccia (2020, p. 32), “[...] um movimento de confluência e de assimilação coletiva".

Um cultivo ético que ativa um cuidado e um espaço-tempo disposto, acolhedor, contaminado pela vontade de poder experimentar, testar, tentar, cooperar e cocriar. Exercícios de aprender a viver não dados nem pensados, mas dispostos a serem vividos em comunhão. É desse chão que temos tentado nascer, inventando outras formas de nos constituirmos nesse corredor de transformações - metamorfoses (COCCIA, 2020).

\section{$3 \mathrm{O}$ encontro com as escritas: assentando o terreno e compreendendo a malha}

Nesse estágio da pesquisa e consolidação do Grupo, visamos identificar e compreender as multiplicidades de forças que se colocam em movimento quando se pensa acerca da seguinte pergunta: Que relações de forças concorreram para que você buscasse a formação inicial docente?

Considerando que o convite para que as participantes do Grupo respondessem à referida pergunta não teve caráter de obrigatoriedade, apontamos que as construções escritas produzidas pelas integrantes do Grupo chegaram como respingos de confiança e de generosidade, por estarem carregadas de uma disponibilidade de quem se experimenta produzindo a construção de uma materialidade-escrita. Ademais é importante sinalizar que não solicitamos às personagens que se identificassem no material, caso assim não quisessem e, ao mesmo tempo, pedimos que fizessem uso de qualquer tipo de expressão escrita que tivessem interesse e vontade ao longo do processo.

Ao total, o Grupo conta com 15 integrantes e obtivemos o retorno de dez delas. Considerando que nós, autoras do estudo, também fazemos parte do Grupo, apenas três não conseguiram submeter seus escritos. As criações foram sendo postadas uma a uma em uma pasta que criamos por intermédio da plataforma Google, especificamente no Google Drive. É interessante pontuar que a maioria das construções escritas compreendeu a extensão de uma lauda, sendo observadas escritas que também demandaram mais páginas para sua mobilização. Sabendo disso, a seguir teceremos um movimento de atenção para o conteúdo do que foi elaborado pelas integrantes do Grupo, aqui denominadas de Fiandeiras, pela via das afecções que se dão na medida em que se experimenta o contato com as mesmas. Para tal, e em correlação à noção de afeto, tomamos o conceito de afecção trazido por Deleuze (2002, p. 56), que "[...] remete a um estado do corpo afetado e implica a presença do corpo afetante, ao passo que o afeto remete à transição de um estado a outro, tendo em conta variação correlativa dos corpos afetantes". Pela via dessa atenção ao que chega, portanto, buscamos ensaiar escritas que dissessem que relações de forças concorreram para que as integrantes do Grupo Fiandar buscassem a formação inicial docente, em suas diferentes áreas. 
Uma das integrantes do Grupo, aqui denominada Fiandeira A, foi a primeira a enviar sua construção e optou por intitular seu escrito como 'Plano B'. Em seu relato, escreve que nunca teve o intuito de ingressar na formação para atuação como docente, e prossegue:

[...] desde os 12 anos queria estudar psicologia e foi meu foco até o ano do vestibular, entretanto, muitas coisas aconteceram no desenrolar e os pensamentos foram mudando. Mudaram coisas no meu interior, visto que passei por uma experiência um ano antes do vestibular morando em outro país por um ano e então alguns verdes começaram a ficar amarelos. (FIANDEIRA A, 2021).

Percebemos que cargas afetivas e de desejo muitas vezes não coadunam com as escolhas de uma vida, as quais envolvem os limites de nossas possibilidades dentro de nosso campo de vida concreta. Contudo, apesar de sua escolha profissional ter se constituído por outro percurso, após ter ingressado no curso de formação docente, passou a encontrar alguns enlaces que corroboraram para sua continuidade no curso:

Ligações foram o meu norte nessa trajetória da docência. Minha vó estava hospitalizada dias antes de embarcar para o México, foi diagnosticada com leucemia e segurou minha mão e disse "Pode ir minha neta, avó vai estar aqui" e realmente quando voltei ela estava ali, estava bem e feliz na medida do possível. Apesar da doença ela está conseguindo cuidar de algumas crianças que não conseguiram vaga na creche ou quando termina a escola os pais não conseguiam buscar. Eu passava todas as tardes com ela, e numa dessas tardes estávamos tomando um café e ela me contou que o sonho dela era ser "professora de creche", mas que nunca teve oportunidade de estudar e então cuidar dessas crianças no momento fazia ela sentir "o coração mais quentinho". Aquilo me chegou de uma forma muito linda, consigo lembrar dos olhos da minha vó brilhando da maneira mais doce que tinha visto. Era lindo ver a minha vó [...] Decidi dar uma chance para o curso, porque entrei direto em cadeiras do departamento de fundamentos teóricos e aquilo me fez notar a docência de maneira nova, de forma bonita igual o olhar que minha avó tinha quando falou do sonho dela. Não, não faço isso pela minha avó, mas não nego que o brilho dos olhos dela talvez seja uma das forças na minha jornada na docência. (FIANDEIRA A, 2021).

Uma docência que tem gesto e olhos de avó. Que encontra paisagem nos sonhos e cuidados de uma avó. Que extraiu brilho próprio a partir do brilho da avó. Uma docência, afinal, carregada de saudades, de lembranças vivas, de certa sabedoria e generosidade de quem se abre à sua própria história: blocos de sensação que avivam e coexistem com o presente. Docência afetada pelos respingos das condições de possibilidades vivenciadas pela Fiandeira A regimes, hábitos, ritmos -, produzindo, portanto, memórias que são vívidas no próprio corpo que também é afetado pela sua historicidade. Contudo, a noção de memória que aqui se mobiliza é a memória do fora, a qual pensa "[...] o passado contra o presente, resistindo-o, visando constituir novos modos de subjetivação, o que só se faz possível por meio de uma dobra do fora do lado de dentro que impacte e force o pensar [...]" (LOBO; MACIEL JUNIOR, 2018, p. 21). Noção de memória que quando ativada-acionada se abre ao devir, a possibilidade desejante de produzir modos outros de se vincular às próprias histórias e vivências passadas, distanciandose de uma memória estratificada. Atenção para a memória como essa chance que se abre de "[...] contração dos tempos: presente, passado, futuro" (COCCIA, 2020, p. 39), modulando um corpo que é memória-metamorfose, rompimento, migração, descontinuidade. Memória como diferenciação.

Tendo essa noção em vista, a partir dos atravessamentos ocasionados pelas ligações afetivas entre a discente e a sua avó, a Fiandeira A afirmou que a docência foi a força que demonstrou que havia outras formas de ouvir os outros: "[...] de acolher de maneira de estar ali para o outro naquele momento e de que as crianças precisam ser escutadas e notadas. Um olhar 
para as múltiplas infâncias e inclusive a minha foi uma grande chave no portal do fazer docente [...]" (FIANDEIRA A, 2021). Com essa escrita, a integrante do Grupo discorreu sobre os caminhos e descaminhos da escolha pela docência enquanto profissão, reiterando que esse ofício também é marcado pelas afecções que fluem nas relações humanas, pelo gesto da escuta e do estar junto - fato que anteriormente a integrante do Grupo percebia apenas inerente ao campo da Psicologia.

A Fiandeira B, em contrapartida, escreveu que a profissão docente esteve presente na sua vida desde sempre, por intermédio e influência de sua mãe, que é pedagoga.

Ser professora nunca foi um sonho quando pequena, mas quando cheguei na idade de decidir que profissão seguir, a pedagogia apareceu como uma das opções, pois me emocionava muito a relação com a pureza das crianças, como elas viam o mundo e trabalhar com elas me parecia algo muito prazeroso. Hoje em dia quando olho para trás, vejo que desde bem pequena tenho recordações de um quadro que eu brincava de dar aulas, para amigos imaginários, para bonecas ou quem estivesse disponível para a brincadeira. Agora percebo a influência de acompanhar o dia a dia de uma professora dentro de casa, como também no colégio, já que estudava na mesma escola que ela dava aulas e sempre visitava sua sala. Não fiz pedagogia para seguir os passos da minha mãe, mas dia após dia, durante a convivência, a profissão foi me encantando, de forma tão natural que eu nem percebi. (FIANDEIRA B, 2021).

Avós, mães, presenças femininas ativas na andarilhagem da vida. Seus jeitos e trejeitos nos respingam, inspiram-nos, subjetivam-nos, tornando-nos algo sempre novo em nós. Seus fazeres e dizeres são marcas evocativas, chegando-nos por todos os lados, produzindo subjetividades que são compartilhadas-multiplicadas no viver junto. Se damos atenção e tornamos ativas estas instâncias em nós, conseguimos dimensionar por onde estamos e por onde desejamos ir. Não se trata de dar sentidos às origens e filiações genéticas, mas de encontrar sempre um devir-mulher em nós, uma força invisível que nos coloque a correr e que nos faça crescer-nascer em novo ritmo.

A influência afetiva da presença-força feminina também pode ser encontrada nos escritos produzidos pela Fiandeira G, que afirmou o seguinte:

Conforme fui crescendo, fui construindo também uma relação de admiração e inspiração pela história da minha mãe, que se desafiou ao aceitar um convite para dar aula, aos seus 17 anos, para quatro séries distintas em uma mesma sala (além ainda de exercer todas as demais funções de uma escola), sem qualquer tipo de formação ou experiência - o que era muito comum acontecer na época, pois pela ausência de profissionais que atuassem no interior das cidades, eram realizadas "buscas" por moradores locais que pudessem exercer essa função. Foi a partir daí, das histórias que ouvi sobre as experiências e os aprendizados que minha mãe teve ao longo desse período, que eu comecei a ter ainda mais interesse em, um dia, poder fazer o mesmo. (FIANDEIRA G, 2021).

Na construção da Fiandeira $B$ e da Fiandeira $G$ percebemos o quanto o ambiente familiar parece ser decisivo no processo de escolhas profissionais. O quanto as conversações e também experiências vividas no compartilhamento e na produção de um vínculo afetivo mais intenso pode vir a criar relações de aproximação com pessoas, coisas e materiais, fazendo-nos, entre muitas coisas, buscar trilhas formativas similares a essas aproximações. Compõem parte dessa trama, novamente, as mulheres, que se tornam visíveis ao ocuparem posições que passam a fugir somente da composição dos espaços domésticos, para, gradativamente, exercerem atividades externas, nas fábricas, oficinas, depois escritórios, lojas, hospitais e escolas. De todo modo, nas escritas das integrantes percebemos que essas figuras ainda, sobremaneira, 
compunham posições dadas como secundárias em nossa sociedade, “[...] de assessoria ou auxílio, muitas vezes ligadas à assistência, ao cuidado ou à educação" (LOURO, 2017, p. 21). O que, portanto, apresenta característica majoritária de uma relação trabalhista de um dado tempo, de uma dimensão histórica.

Ainda, por meio do relato da Fiandeira E, identificamos a presença e a vinculação a uma criança, seu irmão, tomando lugar de destaque na sua escolha profissional:

\begin{abstract}
Meu irmão e eu estudávamos na mesma escola de Educação Infantil e para dormir/mamar, ele tinha que pegar na minha orelha ou na dos meus pais, por isso eu era chamada para a turma dele quando era 'hora de fazer isso', ficava observando as crianças menores. Já no Ensino Fundamental, sempre que podia, eu ia para a turma do meu irmão, 'ajudar'. Quando ultrapassei a idade limite para participar de uma colônia de férias que eu e meu irmão frequentávamos (7 anos, se não me engano), passei a participar como ajudante. (FIANDEIRA E, 2021).
\end{abstract}

Se estamos vivos, há marcas em nossos corpos, sopros atemporais que nos atravessam. A infância enquanto força, enquanto marca, é esse lugar que acessa, aperta e empurra, continuando "[...] a existir como exigência de criação que pode eventualmente ser reativada a qualquer momento" (ROLNIK, 1993, p. 2). Em vista disso, para 'ajudar', conforme a narrativa da Fiandeira F, foi preciso criar e dispor de um corpo novo, uma abertura perceptiva-corporal para adentrar no mundo infantil, ou qualquer outro que se observa e se aproxima. Habitamos, assim, zonas de vizinhanças com crianças, bonecas, professoras, coisas e seres. Logo, por mais que haja codificações a partir das instâncias institucionais e formativas que engrenamsubjetivam as vidas pequenas, conectamo-nos com brincadeiras e modos de existir para inventar pequenos mundos: "[...] minha brincadeira preferida era ser professora das minhas bonecas e, posteriormente, do meu irmão mais novo. Todos os dias quando chegava da escola, eu corria para preparar a minha sala de aula e organizar minha turma" (FIANDEIRA G, 2021).

Marcas que empurram, atravessam e delineiam a escrita do presente. A Fiandeira C, assim como as Fiandeiras E e G, argumentou que desde a infância gostava de brincar de escolinha "[...] com primos, amigos e bonecas, especialmente 'assumindo o papel de professora', no entanto, essa não era a profissão dos meus sonhos naquele momento" (FIANDEIRA C, 2021). Contudo, afirmou que com o passar do tempo e das suas vivências em diferentes escolas de educação básica muitos foram os professores e professoras que a inspiraram a rever sua decisão pela futura profissão. Sobre isso argumenta o seguinte:

Muitos foram os/as professores/as que influenciaram na minha decisão, como uma de biologia que passava os conteúdos de forma clara e animadora, outro com uma fala de que eu tinha o dom para a profissão e outra ainda que dava aulas descontraídas, nessas inclusive, as nossas classes não precisavam estar em fileiras, e isso foi bem marcante por sair de um padrão que segui desde a pré escola. (FIANDEIRA C, 2021).

Vamos percebendo a instalação de uma textura densa e muito heterogênea a partir das instâncias subjetivas das escritas das Fiandeiras. Enquanto autoras, vamos enriquecendo nossa constelação de fios, constituindo uma multiplicidade de paisagens, potencializando modos de habitar a educação. Não há uma única força que, sozinha, perfile as condições para o que determinamos como uma busca pela formação docente.

A prerrogativa do 'dom' ou da vocação - presente na narrativa da Fiandeira C - acaba por aparecer, vez ou outra, nas tonalidades discursivas dos ambientes internos e externos da universidade. Não se trata de analisar o que sustenta ou explica esses discursos, mas de tensionar o quanto essa representação de um bom/mau professor, tomado por condições 'inatas' de 
qualificação, atravessa cada um de nós, produzindo alguns efeitos, a saber: despotencializa e desqualifica o aparato complexo e, ao mesmo tempo, singular de produção de um repertório para a formação docente, do contato com elementos e experiências que permitirão a construção de uma série de habilidades, potências, subjetivações e processos de autoeducação que serão cruciais para se habitar um fluxo de vivências que contribuirão para tornar-se um educador ou uma educadora, ao longo de uma vida - do compartilhamento da própria prática de tornar-se educador e educadora.

Nesse sentido, percebemos, na narrativa da Fiandeira E, a clara importância dos docentes que encontrou ao longo da sua caminhada enquanto estudante, como uma força para a escolha da profissão docente:

Ao longo da minha escolarização, sempre tive grande encantamento, admiração, reconhecimento e respeito pela maioria das minhas professoras, que marcaram de forma muito forte a minha trajetória. Sem dúvida, houveram professores que deixaram marcas negativas, mas certamente foram significativos na minha vida. (FIANDEIRA E, 2021).

Presenciamos, nas escritas das Fiandeiras C e E, o efeito das ações e condutas de professores e professoras em suas caminhadas, o que denota a potência da atuação pedagógica como uma chave que inaugura vontades pela trilha da própria profissão docente por estudantes em processo de formação escolar. A potência da docência como um universo discursivo e não discursivo é capaz de influenciar escolhas profissionais de diferentes indivíduos, induzindo-nos a afirmar as afecções positivas decorrentes de um exercício professoral comprometido e articulador de alegria e de contágio ativo das experiências compartilhadas com crianças e jovens.

Em outro aspecto, a Fiandeira $\mathrm{C}$ afirmou haver uma variação da experiência na medida em que se percebeu "[...] como pessoa", quando complementa: "isto é, o que eu realmente gostaria de ser/fazer, e nos dois últimos anos do ensino médio de fato escolhi seguir na área da educação" (FIANDEIRA C, 2021). O relato da Fiandeira C inaugurou a importância das diferentes etapas da formação escolar para que possam se perceber enquanto seres humanos e também enquanto futuros profissionais habitando o mundo.

Por sua vez, a Fiandeira D assume em sua escrita: "Foram várias as forças que me trouxeram até aqui" (2021). Afirma isso ao considerar que:

[...] desde a infância falava em ser professora acredito que pelo fato de eu ser a irmã
mais velha e sempre cuidar e amparar minhas irmãs menores, enxergava na docência
e em minhas professoras que tive na educação infantil como uma família, lembro até
de uma professora que saiu de licença maternidade e que nós alunos da turma em que
ela lecionava (isso na segunda série, de uma escola de ensino fundamental da periferia
do município de são vicente do sul) [sic] fomos até a casa dela conhecer a filha que
acabara de nascer, algo bem acolhedor e familiar (FIANDEIRA D, 2021).

Novamente, a partir da sua escrita, remete a uma noção de que uma rede de afetos é propulsora de encontros e escolhas que podem nos encaminhar ou não pela docência, seja por intermédio das vias e relações familiares ou pelas vinculações escolares e acontecimentos que nos cercam ao longo do processo escolar. Para muitas crianças, é na escola que se vivenciam os primeiros vínculos relacionais e afetivos para além da família, o que produz efeitos diversos na maneira como vamos arregimentando nosso mundo interno e externo.

Pelo fato da Fiandeira D possuir formação inicial em Ciências Biológicas, seu fazer escritural apresenta os caminhos que a fizeram optar pela formação em licenciatura nessa área 
do conhecimento, destacando seu apreço por animais, fator decisivo para que seguisse nessa área de formação. Ademais, a Fiandeira D também escreveu acerca das suas experiências nos estágios supervisionados na formação inicial, corroborando que nesses espaços são experimentadas múltiplas sensações de alegria e tristeza, sucesso e fracasso, o que sinaliza e consolida a importância da existência de componentes curriculares pedagógicos, como é o caso dos estágios, como multiversos profícuos para o desenvolvimento de aspectos autoeducativos da formação docente.

Em percepção semelhante à da Fiandeira D, a Fiandeira E argumenta: “[...] diversos acontecimentos muito pequenos, sem importância e por vezes imperceptíveis contribuíram para que eu trilhasse meus caminhos e chegasse à graduação no curso de Pedagogia" (FIANDEIRA E, 2021). E revela:

Desde sempre, tive um amor muito grande por crianças, quando pequena, dizia que seria pediatra, com o tempo percebi que a medicina jamais seria uma opção para mim. Como muitas pessoas que escolhem distintas profissões, eu gostava de brincar de ser professora, "dando aulas" para meu irmão mais novo, alguns amigos e até mesmo bonecas [...]. (FIANDEIRA E, 2021).

Ao mesmo tempo, a referida Fiandeira direcionou como uma possível força que interferiu para sua escolha profissional foi ter um período da infância marcado pela presença de histórias, quando afirma: "[...] toda noite meus pais liam para eu e meu irmão dormirmos, no período de desfralde, em que começamos a usar o vaso sanitário, as histórias se tornaram ainda mais presentes em nossas vidas, pois ficávamos por horas sentados, ouvindo-as" (FIANDEIRA $E$, 2021). Essa presença do gesto da leitura, vinculada a uma parentalidade atenta e afetiva, mostra a faceta sutil e quase invisível do privilégio, descrita por Alex Castro (2019, p. 151) como sendo " [...] uma faceta do nosso dia a dia que nos parece naturalizada e normativa, sobre a qual nunca pensamos porque sempre contamos com ela, mas que faz uma falta aguda e pronunciada às pessoas que não dispõem dessa vantagem”.

Ao mesmo tempo, a Fiandeira E também evocou uma série de situações que estiveram atuando como empecilhos para a escolha pela docência:

\footnotetext{
No início do Ensino Médio, quando tanto a escola, quanto outras pessoas passam a exercer pressões e cobranças acerca da faculdade e do futuro, me senti perdida e sem saber o que fazer. Diversos cursos passaram pela minha cabeça: nutrição, arquitetura, moda, jornalismo... Mas em uma aula, uma professora falou sobre sua própria profissão e pensei comigo mesma "como nunca pensei em ser professora", desde então, escolhi fazer Pedagogia e não pensei mais em outros cursos. A maioria dos meus professores ficou orgulhosa e me deu muito apoio para seguir. O incentivo dos meus pais também foi fundamental, apesar de muitas pessoas ao nosso redor criticarem minha escolha pelo fato de ser pouco valorizada e por acreditarem que eu tinha potencial para fazer 'algo melhor', meus pais sempre me apoiaram muito e me disseram que eu tinha que escolher o que me fizesse feliz, independente de qualquer outra coisa e principalmente da opinião alheia. (FIANDEIRA E, 2021).
}

Com o referido fazer escritural é possível identificar a presença de uma representação que paira e se propaga no ambiente social e que, muitas vezes, atravessa a não escolha pela carreira docente. Uma noção de 'pouca valorização' - que imaginamos estar caracterizada pela relação salarial e um 'status' de despotencialização social - que surge e acaba por interditar vontades e anseios justamente pela prevalência de uma compreensão que pensa o sucesso como relação única com poder aquisitivo, reconhecimento ou ocupação de lugares de poder. 
Na medida em que a discente foi se colocando em contato com a formação inicial docente, considerou o seguinte:

\begin{abstract}
Com o tempo, fui percebendo a docência como uma profissão capaz de transformar o mundo em um lugar mais justo e com mais oportunidades para todos. Hoje, entendo a docência como uma profissão fundamental, com valor social imprescindível. Apesar de não pensar a Pedagogia como um 'dom' nato, pois requer formação, dedicação e estudo constante, não consigo me imaginar fazendo outro curso e sinto que tudo na minha vida foi se encaixando 'naturalmente' pra que eu estivesse onde estou, vivendo experiências fundamentais não só para minha profissão, mas também para minha vida. Sou realizada com a profissão que escolhi e espero ter coragem, maturidade e dedicação suficientes para exercê-la da melhor forma possível. (FIANDEIRA E, 2021).
\end{abstract}

Com base no escrito da Fiandeira E, é possível visualizar sua compreensão da formação superior em Pedagogia como um processo que é desenvolvido a partir da mobilização e aperfeiçoamento de uma série de aprendizagens inerentes a área, o que, portanto, se distancia de uma compreensão da atuação docente como um dom-dádiva, ou seja, como uma aptidão natural que se encontra vinculada a um número restrito de sujeitos. Perspectiva que vem ao encontro de reiterar a potência que a própria formação inicial docente possui como um lócus interessante e significativo para a produção de um repertório formativo que dê conta de apresentar ao docente em formação um horizonte de elementos que lhe permitam entrar em contato com a docência.

A Fiandeira F, por sua vez, apresentou que sua escolha pela docência esteve relacionada com a vinculação em uma instituição de ensino privada que fornecia bolsa total para estudantes do Curso Normal. Segundo escreveu: “[...] no início eu fiquei receosa e não queria cursar o magistério, já que pensava em me graduar em moda ou algo relacionado as artes" (FIANDEIRA $F$, 2021). Com o passar do tempo, a Fiandeira $F$ passou a se aproximar da área e, no ano de 2018, começou a cursar Pedagogia. Assim, direcionou ao Curso Normal e também às suas práticas docentes a escolha pela Pedagogia, contrastada com a "[...] vontade que toda professora tem de mudar o mundo, de mudar a vida de um aluno para melhor, de fazer a diferença na vida de alguém" (FIANDEIRA F, 2021). Pulsações que desencadeiam o efeito de polinização, abrindo vias ativas de ser docente, fazendo germinar novos mundos em educação.

A Fiandeira $\mathrm{G}$ escreveu que, ao voltar seu pensamento para as memórias da infância, o que encontrou foi: “[...] minhas memórias escolares, memórias de 'ser aluna'. Isso porque desde pequena gostei muito daquilo que a maioria das pessoas da minha idade não gostava: estar na escola e poder ser/sonhar a partir dela" (FIANDEIRA G, 2021). Seu relato dimensiona o quanto gostar de estar na escola, sentir-se acolhida e cuidada, produz uma força de confiança alegre, a ponto de suscitar a busca para atuar profissionalmente nesse território. Parece-nos que isso expõe a complexidade da escola, de ser esse lugar de possibilidades infinitas de agenciamentos de diferentes vetores de subjetivação. De não compor e ser composto tão somente por marcas definidas por encontros tristes, mas, ao mesmo tempo, de possibilidades e afecções alegres, que vão ao encontro de mobilizar um senso de 'querer estar perto', de construção de comunidade de pertencimento.

Há algo aí que nos move, em conjunto, ao lermos as Fiandeiras: encontrar esse polo ativo é o que preserva nossa potência vital em vida (ROLNIK, 2018), acessando e inventando maneiras de lermos e decifrarmos nossos mundos para mais intensamente vivê-los. Um aspecto importante inaugurado pela Fiandeira G, ao longo de sua escrita, também passa por isso. Segundo escreve, um dos aspectos mais marcantes é o quanto ela se afirma comunicativa, e o quanto gosta de conversar e também de ter com quem fazer isso, pois, como aponta: “[...] são 
as relações que eu estabeleço em minha vida que me motivam a ser/ir em busca de, são estas relações de troca que me movimentam, são estas trocas que me transformam. E, para mim, a docência é tudo isso: movimento, troca e transformação" (FIANDEIRA G, 2021). Com essa construção de compreensão em malha, é possível afirmar que a ação docente, na perspectiva da Fiandeira $\mathrm{G}$, faz-se em meio às relações humanas e não humanas que nela se delineiam, o que denota que uma força importante para sua escolha profissional passa por encontrar um campo de atuação que lhe dê a chance de ser quem se é com potência, explorando a fluidez de um modo de ser que permita vazar as múltiplas forças que a habitam.

A partir da atenção para as multiplicidades que ecoam das escritas das Fiandeiras, tecidas por meio de composições interessadas em criar superfícies rizomáticas, é que intensivamente nos conectamos com heterogeneidades que dão vazão ao Grupo de Estudos e Pesquisas em Educação Fiandar. Por isso, nascemos mais uma vez, com a força de um fluxo interessando em continuar apostando no movimento, na partilha, na confiança da transformação, seguindo pistas que culminem na potência flutuante dos estranhamentos, das aprendizagens-metamorfoses.

\section{Considerações Finais}

O presente fazer escritural ensaístico dimensionou as relações de forças que concorreram para que membros de um Grupo de Estudos e Pesquisas em Educação escolhessem a docência como formação inicial em nível superior. De modo geral, com este estudo foi possível compreender que: 1) Os vínculos e as experiências vivenciadas no cerne dos ambientes parentais e/ou familiares tomam lugar de destaque em como as Fiandeiras perceberam e buscaram sua futura ação profissional; 2) As afetações que os professores e as professoras que perpassaram por suas vidas produziram em seus corpos como força importante para a escolha da docência como profissão; 3) A experimentação vivenciada na infância, nas brincadeiras, nas aulas direcionadas às bonecas e aos irmãos, como promotora de uma alegria que ficou registrada na memória corporal e afetiva dessas professoras e futuras professoras; 4) As representações sociais estratificadas que pairam sob a docência por vezes se caracterizam como um ponto problemático que, ocasionalmente, impede e dificulta a opção pela formação superior em licenciatura.

Com isso, o presente estudo permitiu delinear que a escolha pela docência enquanto profissão deste território formativo - o Grupo de Estudos e Pesquisas em Educação Fiandar é marcada por diferentes polifonias e multiplicidades que demandam cultivarmos uma permanente atitude ética que respeite e permita às Fiandeiras estarem modulando-se livremente, com base em suas próprias leituras de mundo e também de proximidade com a docência.

Reativar esses gestos de escrita é perceber a duração do tempo, o retraçar de um caminho através da experiência vivida. Nesse sentido, "o ato de contar resgata a memória para infinitos encontros que se realizam nas histórias. Por isto o dizer, o contar é uma arte do fazer, do produzir e do transformar uma realidade que já existe em função do que outrora foi falado" (MAIRESSE, p. 2003, 267). Nós, autoras, 'ouvintes' desses contos-escritas, compomos com, pensando e produzindo novas práticas e afetos entre nós. O fazemos, pois, estamos a nascer juntas, crescendo, compondo, desconectando, ativando variações intensivas que nos tornam sempre outras a se metamorfosear.

Ativadas por uma pergunta, aprende-se a aliar eventos e experiências de suas próprias vidas às vidas dos que as antecedem, às vidas que constituíam suas vidas, "[...] tomando recursivamente os fios dessas vidas passadas no processo de fiar a sua" (INGOLD, 2015, p. 
237). As linhas de passado e presente das malhas das integrantes juntam-se agora ao Grupo, para dar continuidade ao conhecimento que é gerado neste espaço, “[...] subsistindo na corrente da vida e da consciência" (INGOLD, 2015, p. 237).

Construir a presente tessitura com e a partir das escritas das integrantes é poder produzir e acompanhar a constelação afetiva da qual sua vida faz parte, criando e constituindo essa própria constelação. Com a oportunidade do uso da linguagem escrita, acessam-se oralidades e os processos de conhecer e aprender que envolvem o campo experiencial e emocional dessas vidas, dando a ver o próprio movimento de criar-se no processo de atenção para sua historicidade ao escrever. É aí que nós nascemos sob outras formas. É aí que a malha se expõe, se estende e se põe em continuidade-descontinuidade, dando a ver a multiplicidade de territórios, sonhos, delírios, crenças, emoções, pessoas, seres, acontecimentos, forças, afinal, que nos compõe e permite habitar o mundo.

Não se desejou, porém, determinar pontos de passado e origens, ou futuros e destinos nas escritas do Grupo, mas encontrar os filamentos das linhas de emergência do hoje, os quais seguem correndo concomitante e horizontalmente. Isso nos ajuda a encontrar o outro e a nós mesmas sempre por uma concepção mais aberta e incerta, onde todos estamos improvisando caminhos, embarançando-se aqui e desembarançando-se ali.

Ainda que cada fazer escritural mobilizado pelas integrantes conte-acione vivênciasmemórias sobre uma vida, entendemos que é como se não pudéssemos mais separar a historicidade de cada uma, daquela do mundo, com cada vida expressando uma atividade que diz de um elo entre as linhas da malha e na corrente de transformação da vida (COCCIA, 2020). Há um pertencimento recíproco dos afetos, das emoções, das reminiscências contadas que não podem mais ser identificadas, congeladas e individualizadas como de um sujeito isolado: metamorfoseadas, comunicamos e existimos, agora, de dentro desse rico conteúdo compartilhado, intensivo e diferencial.

As diferentes e múltiplas trajetórias que delineiam os acontecimentos de vida, portanto, constituem a própria malha do Grupo de Estudos e Pesquisas em Educação Fiandar, por estarem afetando e contribuindo, por meio das suas próprias afecções, para que seja possível mobilizar novos processos educacionais, capazes de inaugurarem inéditos no mundo e, inclusive, na docência e na educação escolar.

\section{Referências}

CASTRO, Alex. Atenção. Rio de Janeiro: Bicicleta amarela, 2019.

COCCIA, Emanuele. Metamorfoses. Rio de Janeiro: Dantes Editora, 2020.

CORRÊA, Guilherme Carlos. EJA, educação e escolarização. In: ANPED Sul 10. Anais X Reunião Científica da ANPED, Florianópolis, Universidade do Estado de Santa Catarina (UDESC), 2014.

DALMASO, Alice Copetti; RIGUE, Fernanda Monteiro. Fiandar: modos de habitar - pensar, criar, viver - (n)o ambiente universitário. Revista da Faculdade de Educação, v.34, n.2, 6179. https://doi.org/10.30681/21787476.2020.34.6179

DELEUZE, Gilles. Espinosa: filosofia prática. São Paulo: Escuta, 2002.

FOUCAULT, Michel. Microfísica do poder. Rio de Janeiro: Paz e Terra, 2015. 
INGOLD, Tim. Estar vivo: ensaios sobre movimento, conhecimento e descrição. Petrópolis: Vozes, 2015.

LARROSA, Jorge. O Ensaio e a Escrita Acadêmica. Educação e Realidade, Porto Alegre, v. 28, n. 2, p. 101-115, 2003. Disponível em:

https://seer.ufrgs.br/educacaoerealidade/article/view/25643. Acesso em: 29 mar. 2021.

LOBO, Amanda Souza Ávila; MACIEL JUNIOR, Auterives. Memória, subjetivação, resistência e fora em Foucault. Aprender Caderno de Filosofia e Psicologia da Educação, v. 2, p. 9-22, 2018.

MAIRESSE, Denise. Cartografia: do método à arte de fazer pesquisa. In: FONSECA, Tania Mara Galli; KIRST, Patrícia Gomes (org.). Cartografia e devires: a construção do presente. Porto Alegre: UFRGS, 2003.

ROLNIK, Suely. Pensamento corpo e devir - uma perspectiva ético/ estético/ política no trabalho acadêmico. In: Cadernos de subjetividade. São Paulo: PUC 1993, nº 2.

ROLNIK, Suely. Esferas da insurreição. Notas para uma vida não cafetinada. São Paulo: n-1 edições, 2018.

Recebido em julho de 2021.

Aprovado em outubro de 2021. 